\title{
Implications and Benefits of a Long-Term Peer Debriefing Experience on Teacher Researchers
}

\author{
Candace Figg \\ Brock University \\ Melanie Wenrick \\ California State University \\ Christy Youker \\ Educational Consultant \\ Joanne Heilman \\ Walden University \\ Cynthia Schneider \\ The University of Texas
}

\begin{abstract}
Peer debriefing ensures the trustworthiness of a qualitative research study. Through peer debriefing, the researcher explores the research design, data collection process, and data analysis while colleagues, serving as critical friends, encourage the researcher to examine the research process from multiple perspectives. This paper examines experiences in a peer debriefing group formed by five female teacher researchers as a part of their graduate requirements for doctoral work, and their continued association as they pursued their professional goals. Three themes emerged based on the analysis of team meeting minutes, reflective journal logs, and case reports constructed reflectively by the five participants. These were: (a) essential elements of a successful peer debriefing group are commitment, continuity, and individual expectations being met; (b) participation can serve as an important development step in preparation as a professional researcher and educator; and (c) academic and emotional support provided by a peer debriefing group is a motivating factor leading to researcher's perceptions of success. These themes highlight the benefits of including peer debriefing as a part of the action research process of teacher researchers as a means of dealing with the 'messiness' that novice teachers researchers encounter when conducting action or self-study research.
\end{abstract}

Key Words: Peer debriefing, critical friend, teacher researcher, teacher research methods, qualitative research methods

Dr. Candace Figg is an assistant professor of Technology Education at Brock University, St. Catharines, Ontario; Dr. Melanie Wenrick is an assistant professor of Mathematics Education at California State University, Fresno, California; Dr. Christie Youker is an Outreach Consultant for the San Angelo Museum of Fine Arts, San Angelo, Texas; Dr. Joanne Heilman, is a faculty member in the Richard E. Riley College of Education, General and SelfDesign PhD Program at Walden University; and Dr. Cynthia Schneider is a researcher at the Charles A. Dana Center of Research and Evaluation at the University of Texas, Austin, Texas.

Email: candace.figg@brocku.ca 


\section{Implications and Benefits of a Long-Term Peer Debriefing Experience on Teacher Researchers}

\section{Experience on Teacher Researchers}

Effective professional learning opportunities for teachers are job-embedded (Joyce \& Showers, 2002), driven by the learning needs of those teachers, and occur over time (Fullan, 1995; Little, 2002). Professional development that includes reflection and collaboration has also been identified as successful (Bonner, 2006; Kang, 2007; Briscoe \& Wells, 2002; Kraft, 2002), in providing teachers with "a deeper understanding of themselves professionally and personally" (Glazer, Abbott, \& Harris, 2004, p. 43). However, professional development experiences that result in changes to teacher practice embed critical reflection on practice through choice of investigation of situations deemed problematic by the teacher (Kraft, 2002; Lytle \& CochranSmith, 1990), combined with critical examination of specific constructs of individual teaching practices (e.g., using results of diagnostic activities to determine next steps in instruction, or learning how to promote active learning) (Briscoe \& Wells, 2002; Kang, 2007; Savoie-Zajc \& Descamps-Bednarz, 2007). Therefore, teachers who conduct various forms of classroom research, or teacher researchers (as described by May, 1993), have been informally participating in quality professional development on their own-a trend many school boards across North America are examining as a way to enhance teacher learning while providing local professional expertise (Fletcher, 2002; Meyers, Rust, \& Paul, 2006). Realizing the potential for teacher research, based on action research and qualitative methods, to influence change in teacher practice, these same boards and organizations are investigating methods that best support and encourage the use of teacher action research in the classroom (Atay, 2008, Zeichner \& Klehr, 1999).

\section{Teacher Action Research as Professional Development}

In the last decade, there are a few projects that highlight teacher action research and the support by boards and organizations to support teachers' knowledge about the methods, techniques and strategies of action research. For example, the Elementary Teachers Federation of Ontario (ETFO) launched a project, called Teachers Learning Together, in 2006, where 50 teams of teacher researchers self-selected and conducted research projects with the support of university facilitators (Figg \& Jaipal, 2009). The project was able to demonstrate on a provincial-wide scale that, as Baumann and Duffy (2001) stated, practitioner research has the power to "inform teachers about their classroom worlds and to transform their thinking and actions" (p. 613) in order to improve teaching practice and impact student achievement.

As well, Zeichner and Klehr (1999), who presented studies of teacher researchers supported by school boards in five states, found that teachers who conducted action research became more confident in their ability to conduct research and used their findings to make informed decisions about what works in the classroom. Flake, Kuhs, Donnelly, and Ebert (1995) described the development of teachers who were able to create knowledge that empowered them to "participate in professional dialogues and direct their own professional development" (p. 407) from experiences in a university program that embedded action research techniques throughout the course experiences in their Master of Arts in Teaching program.

These and other positive examples of using action research to impact teacher practice, 
have resulted in teachers being encouraged to participate in action research as a means of professional development. Their efforts have illuminated the 'messiness' of the research process, specifically the struggle of novice teacher researchers to use qualitative methods to interpret and make sense of data (Cook, 1998). Even though Baumann and Duffy (2001) have stated that teacher research primarily uses "practical, efficient, qualitative methods recommended by other teacher researchers, with perhaps a quantitative tool added in" (p. 611), Cook (1998) calls for additional research to provide context to the 'messiness' of the different aspects of qualitative research by describing the process "more expansively and candidly" in the literature, rather than having these aspects "tidied away" (p. 107).

One of the 'messy' areas of research is ensuring rigor in the action research process. The use of a 'knowledgeable other' to ensure credibility and trustworthiness of the research is one strategy associated with qualitative research. Erlandson, Harris, Skipper, and Allen (1993), as well as Lincoln and Guba (1985), identify this 'knowledgeable other' as a peer debriefer. Graduate students conducting qualitative research, usually as a part of their graduate experience, are often required to locate one or more 'peer debriefers' to serve as a support mechanism to both challenge and encourage each member throughout the research process and to assure the credibility of a qualitative research study (Creswell, 1998; Ely, Anzul, Friedman, Garner, \& Steinmetz, 1991; Erlandson, Harris, Skipper, \& Allen, 1993; Glesne, 1999; Lincoln \& Guba, 1985; Spall, 1998; Spillett, 2003). Others identify this 'knowledgeable other' as a critical friend (Gordon, 2006; Smith, 2004; Wennergren \& Ronnerman, 2006), who challenges and critiques interpretations in order "to reduce or even remove blind spots" associated with qualitative data analysis (Gordon, 2006, p. 5). Peer debriefers and critical friends serve a similar function-to ensure the success of the research by providing an external perspective from a knowledgeable source to ensure rigor in the trustworthiness and credibility of the research (Costa \& Kallick, 1993).

In action research studies, teacher researchers report seeking confirmation of ideas or interpretation of data from outside sources, or a 'knowledgeable other.' Baumann and Duffy (2001) observed that the 34 teacher research studies in their analysis often included consultations with experts, conferences with colleagues, or informal conversations with other teacher researchers. Each of the 50 ETFO Teachers Learning Together project teams commented on the value of having the university facilitators available to act as an objective observer of their research process, and serve as a consultant to make research decisions, bring fresh perspectives to data interpretation, discuss next steps, or even provide moral support during the research process (Figg \& Jaipal, 2009). Yet, these teacher researchers did not recognize the use of a peer debriefer as an important strategy that should be part of the formal action research process in order to support the credibility and strength of their research. There is a need to explain the benefits and best practices for engaging in peer debriefing with a critical friend or peer debriefing group, especially as it applies to teacher research, in an effort to illuminate the 'messy' aspects of action research.

\section{Methods}

This study employed qualitative methods (Cresswell, 2006; Patton, 2002) to examine the experiences of a peer debriefing team of teacher researchers, which successfully functioned as a network of critical friends over a period of several years, in order to provide insights into how teacher researchers, and their research, are impacted by their participation. 


\section{Participants}

Five female doctoral students enrolled in various curriculum and instruction programs in a faculty of education at a large research institution from 1999-2002, formed a peer debriefing group of critical friends. Each was involved in different areas of the Curriculum and Instruction doctoral program, and each had come to the program with background experience as teacher researchers.

Catherine's background included one year teaching Grade 7 Science, four years of museum teaching experience, and two years teaching at the university level. Her specialty was Science Education with an emphasis on Museum work. She was researching why and how elementary teachers used community resources in teaching science. Carly's background included twenty-two years of teaching experience as an elementary, music, visiting, and library teacher. She was specializing in Instructional Design and Technology investigating the impact of techenhanced professional development on teachers' beliefs about teaching and daily instructional practices. Jeanne was also in the Instructional Design and Technology program. With her background of eleven years teaching middle and high school English, and five years as a staff development trainer, she was investigating evaluation research, best practices for teaching and learning online, and best practices for classroom integration of technology. Isabelle and Susan were both in the Math Education doctoral program. Isabelle, who had served as an elementary teacher for six years, was investigating how elementary-aged children learn mathematics, specifically fractions. Susan, who had taught six years as a college instructor in development and college level mathematics, was evaluating curriculum implementation and professional development for specific Mathematics curriculum programs.

\section{Procedure}

\section{Structure and focus of the peer debriefing meetings from 1999-2002.}

The team usually met weekly during the semester and every other week during the summers. During the school year, they met on campus in their workplaces. During the summer, they met at restaurants for lunch. Meetings consisted of each member taking turns sharing progress on research projects, asking questions, getting feedback, or discussing issues or concerns-whatever was needed. The team also spent a few minutes talking about their personal lives in order to understand the other factors influencing or impeding each other's work. One member was responsible for taking, typing, and emailing the notes to the rest of the group. The amount of time spent on each project varied based on individual needs. Sometimes, the team spent most of the meeting time working on one or two projects, but everyone had an opportunity to share. Team interactions and feedback provided during the meetings targeted the learning needs of each team member, as well as the group as a whole, in order to build a strong knowledge base about research methods and strategies, while developing skills for supporting others in the research process. This balance allowed all members of the team to experience a safe place both professionally and personally.

For example, in one meeting, Catherine was dismayed that her dissertation advisor had decided the pilot study, that Catherine had conducted using naturalistic inquiry methods, would need to be redone using more interpretive techniques. Carly suggested that Catherine re-analyze the data from the pilot using interpretative methods since the advisor suggested she use these 
methods for a new pilot study. Additional feedback from Susan and Isabelle supported this idea by describing how this could be done.

In another meeting, the team discussed ethnographic methods and the relationship to methods used in other research paradigms - especially the naturalistic inquiry methods most of the group members were using. The discussion grew out of a query from Jeanne who was exploring the possibility of using ethnographic methods for her dissertation research. The team members agreed to each do a bit of review of the methods and bring that information to the next meeting. Notes from the following meeting describe how team members brought information, articles, and comments from professors interviewed about ethnographic methods, to share with the team.

Transcripts of another meeting describe the angst that Susan was experiencing in the middle of her dissertation work. Her dissertation advisor informed her that she should drop the qualitative component of her study and focus only on the quantitative results. She was encouraged by all of the team members to continue to meet with the team to explore her own feelings about how her research process was evolving. In addition to providing moral support, other meetings allowed Susan to share her quantitative data analysis with the team for feedback on appropriateness of instruments in providing data that would inform her research question. These are only a few of the examples of the type of interactions and depth of feedback documented in the minutes of the peer debriefing meetings, emails, personal journals, and reflections recorded for the group.

\section{Online structure of meetings to facilitate preparation of case studies for this paper.}

The close bond developed during the participation in the peer debriefing team continues today, even though team members are scattered across North America (California to Texas) and Canada. When the team decided to explore the relationship and impact of participation in the team on members' lives and research, team meetings were conducted virtually, using various online tools (Skype, Brigitte, GoToMeeting), as well as telephone conference, and email. The format remained the same in that members shared case study reports or discussed coding of unitized texts, decided upon next steps, and made sure that everyone had a chance to speak. Minutes of these meetings were recorded using the log features of the online tools and transcription of telephone conferences. An essential part of getting back into the routine of the team meetings was the sharing of what was happening in individual team members' personal lives.

\section{Data Collection}

Data sources included 33 team meeting minutes, 5 personal journals (one from each member), 48 archived emails, and 34 personal reflections from 1999-2002. After reviewing the 1999-2002 data sources, each team member wrote a personal account of her experience with the peer debriefing group - a personal case report written in 2008 based on their current perceptions of their experiences with the group during their earlier association as graduate students from 19992002. This reflective narrative asked participants to respond to the open-ended prompt, "Describe your experience in a peer debriefing group." The purpose was to collect information regarding what the members now view as important benefits of their participation and its impact on their scholarship and teaching today. 


\section{Data Analysis}

The case study process, as described by Schwandt (1994), uses an "instance of a phenomenon selected for study" (p. 12) to provide rich context of the phenomenon that furthers "understanding of a particular problem, issue, concept." (p. 13). Each team member analyzed their own narrative in order to build a personal case providing rich context for the reflective process. After writing the first draft of their individual narrative, each member grouped her thoughts into coded categories and generated emerging themes for her own case study report. Each member then rewrote her case study report to elaborate upon the themes identified. At this point, team members shared their reports with each other.

\section{Cross Case Analysis}

Cross-case analysis of resulting cases provides the researcher with an opportunity to investigate a specific phenomenon in multiple settings; therefore, a content analysis was conducted across the five cases (Patton, 2002; Yin, 2008; Miles \& Huberman, 1994). Two researchers unitized the data from the five 2008 case study reports, as well as the 1999-2002 transcripts from the group meeting minutes, personal journals, archived emails, personal reflections, in order to identify key descriptor phrases. These key descriptors were then aggregated and categorized into general coding categories, which were used to generate emerging themes, or "general statements applicable to the specific context under investigation" (Erlandson et al., 1993, p. 61). The coding process and emerging themes were presented to the remaining team members, who served as the peer debriefers, for comments and clarification. The process of generating data, unitizing data, and developing categories and themes from the data, continued until reaching thematic saturation, or the point at which no more new categories and themes made themselves apparent (Erlandson et al., 1993). A sample of the category generation process from the unitized data is included in Table 1.

Table 1

Sample of Data Analysis: Category Generation

\begin{tabular}{l|l|l|l}
\hline Theme & $\begin{array}{l}\text { General Coding } \\
\text { Categories }\end{array}$ & $\begin{array}{l}\text { Key Descriptor } \\
\text { Phrases }\end{array}$ & Example of Units of Data \\
\hline $\begin{array}{l}\text { Preparation for } \\
\text { role as a } \\
\text { professional } \\
\text { researcher and } \\
\text { educator }\end{array}$ & $\begin{array}{l}\text { Professional } \\
\text { Development }\end{array}$ & $\begin{array}{l}\text { Academic } \\
\text { Support }\end{array}$ & $\begin{array}{l}\text { It also helped me keep on-task } \\
\text { because I knew that I was expected to } \\
\text { have completed a certain portion of } a \\
\text { project by our meetings. (Catherine) }\end{array}$ \\
\cline { 3 - 4 } & & $\begin{array}{l}\text { Research Skills } \\
\text { Learned }\end{array}$ & $\begin{array}{l}\text { Working in this group helped me } \\
\text { learn how to analyze my classmates } \\
\text { work critically, give valuable } \\
\text { feedback, and accept constructive } \\
\text { criticism on my work. (Isabelle) }\end{array}$ \\
\hline
\end{tabular}

For purposes of this paper, the resulting themes that emerged from the cross-case analysis are detailed in the findings. 


\section{Findings}

Three themes emerged from this research: (a) essential elements of a successful peer debriefing group are commitment, continuity, and individual expectations being met; (b) participation can serve as an important developmental step in preparation as a professional researcher and educator; and (c) members of the group need to feel academically and emotionally supported. We present these themes separately, with evidence from the full case study reports constructed from the 1999-2002 data sources.

\section{Theme 1: Essential elements of a successful peer debriefing group are commitment, continuity, and individual expectations being met.}

Commitment as a foundation for successful group interaction was a unifying theme identified in all five team members' reports. Catherine states this clearly when she says, "Above all else, I feel that commitment to the group and to one's professional endeavors was most important." The term commitment was not used to describe a singular aspect of the group experience, but referred to several. The first of these was a simple commitment to attend meetings. Susan states, "I believe we all took responsibility to attend each week and bring something to the discussion that would forward our individual work." Jeanne also noted the importance of attendance when she commented, "I was committed mentally and physically to attending research group meetings," even in the midst of her serious health challenges. Isabelle explained that reading the minutes when she could not be present helped her feel somewhat connected. Yet, she realized that, "I still felt like I was missing out by not being there." When personal issues took group members away physically from meetings, participants noted feeling 'off-track' which resulted in a sincere effort to attend next time.

Commitment also referred to active participation in the group, in terms of sharing expertise, taking notes, reviewing work and often simply listening. Carly states, "Together, we set up consistent meetings with the shared expectation that team members would come prepared to share and prepared to assist." Members described how much they valued and directly benefited from the feedback received from during team meetings, as well as how they were always more than willing to listen and review others' work. Susan reflected, "There was a willingness to listen even when we did not understand all of the details, and a willingness to give of our time both during the meetings and outside of them whenever we could." The case study reports describe the understandings that all felt regarding what it meant to be a part of a team that would benefit all members, even if that meant putting in extra time. Carly explained, "There was an unspoken assurance that each member would have time to report-regardless of how long the meeting had to run."

Commitment to attendance and active participation could not be separated from the mutual respect team members expressed having (and continuing to have) for each other. Catherine explained,

We are five women that might not have come together as friends, were it not for this group. We were all so very different in terms of our fields of research interest, personal lives and backgrounds, and types of research methods. We respected this diversity, and even counted on it to give us deeper perspective on our own journey through the research process.

Catherine unequivocally added, "I cannot help but think of the profound respect we had for each 
other as an essential component of our group."

When reflecting upon commitment and respect, failed previous groups and the group members who joined and dropped out were mentioned by all. When Jeanne reflected on her other group experiences, she noted that, "I believe these groups were not as successful as [the team participating in this study] because they lacked commitment, diversity, and the interpersonal chemistry that made our group flourish." Catherine discussed her frustration with a prior team by explaining that one of her team members was a friend but she "was unreliable in terms of following through on promises to revise work or turn in portions of her project." There were also members in the team participating in the study who joined, but dropped out, after one to three months. Isabelle, Catherine and Carly speculated that it was a lack of commitment. Isabelle added, "When I asked for advice, they were not around to give any, and I did not learn from their experiences," whereas, she sums up the respect team members had for one another, saying, "I always felt like I could count on the other members in my group to help, and I was there for them too."

Very closely tied to commitment is continuity and prolonged engagement. Team members noted that they were not simply in the group for a semester, but for the duration of their journey through graduate school. Susan even continued after she graduated and was working on projects at her job. The team took steps together to further this continuity and long-range planning. During the second year of the team meetings, the team began a task chart that kept track of short and long-term team goals, which was updated weekly by the note-taker in order to keep track of team progress. Members attributed steps such as this, as one of the ways the group achieved their individual and team goals. As Susan explained, "The process we used, weekly progress reports, transitioning into required action steps, be they small or large, short or long, supported four of the members of our group to successfully defend their dissertations." Carly added, "The process provided crucial continuity to the work of the group as well as a valuable record of individual progress."

Group consensus identified a third component for a successful peer debriefing groupindividual expectations were met. Within the first few meetings of this peer debriefing team, expectations as to how the group would function, so that maximum benefit could be gained from participating, were established. This included the fact that all members expected that they would provide and receive feedback while they collected and analyzed data for their respective research projects, especially as several of the members-Carly, Catherine and Isabelle-were required to be in a peer debriefing group to add credibility to their research process. However, Susan, who was conducting quantitative research, explained her reasons for participating as "an effective way to continue to learn more about qualitative research and, at the same time, use their meeting discipline to support my research goals."

Catherine had realized the potential of a peer debriefing group, even though her first experience was not optimal. She expected this team to "provide structure and support in graduate school" because "working on projects, much less a dissertation, could often seem like a solitary journey." Jeanne explained that her experiences with an earlier peer debriefing group she had belonged to, as well as this team, had "provided a sounding board for the research, from forming the research questions, completing human subject's paperwork, through data generation and analysis and finally moral support and encouragement to persevere."

A consistent statement throughout each of the cases was that each member of the team expected that the participants in this newly formed peer debriefing group would be extremely committed, and be willing to provide quality feedback. Carly acknowledged, "I found that I 
expected a certain level of commitment from the others in relation to keeping the group active and productive." Therefore, not only was 'committed participation' an essential component of this group, it was an expected essential component.

\section{Theme 2: Participation can serve as an important developmental step in preparation as a professional researcher and educator.}

Even though the members of this group have all chosen different professional paths, all revealed that they have been able to apply what was learned from team participation to their current professional lives. All team members remarked on the skill development that resulted from participation in the peer debriefing process, specifically mastering collaborative, communication, and research writing skills, as well as the awareness gained regarding different fields and types of research. Susan felt she was better prepared to field questions from her dissertation committee members and gained the "confidence to discuss these concerns with [her] chair or other committee members" after reviewing aspects of her dissertation with her peer debriefing group.

Similarly, Isabelle saw the benefits of learning to communicate about her research:

I also developed my ability to talk about my research. This prepared me for the interviewing process as well as for my on-going work with colleagues as we discuss effective teaching strategies and develop new courses for our teacher education program.

Catherine also felt she learned how to better communicate about her research strategy to othersespecially skeptical committee members. By answering her peer debriefing group's questions, she was more prepared to discuss her research: "My peer debriefing group helped me answer [my committee members'] questions and feel confident about my research approach."

Group members honed their written communication skills through reading and providing feedback on each other's work. Isabelle felt she was better able to handle constructive feedback:

I grew as a writer and editor. Before working with a peer debriefing group, I was not comfortable with getting feedback from other people because I tended to take criticism personally. I learned how to receive and appreciate constructive criticism about my writing and how to address suggestions to make my writing stronger and clearer....I also developed my skills in giving feedback to other people. I write more specific comments that help my colleagues and students clarify their ideas.

In addition, working together allowed participants to a reach a deeper understanding of the different ways in which people operate and think, specifically as applied to different disciplines and forms of research. Team members explained that they learned about different fields in education — math education, science education, and instructional technology — as well as explored opposite ends of the spectrum in terms of research paradigms and strategies. Susan's quantitative study employed the use of hierarchical linear modeling and Catherine's naturalistic inquiry study was rooted in a constructivist paradigm. As Isabelle explained, "I felt like I was learning a little bit more about other areas by hearing about and reading excerpts from everyone else's projects."

Team members described how they had learned to appreciate and see the benefits of different research paradigms and research strategies. Susan reflected on insights gained from reviewing the qualitative studies of her fellow group members, "In reviewing my colleagues' work, I was able to experience first-hand the difficulties of reducing large amounts of descriptive data down to themes and sometimes metaphors." Isabelle commented on the complexities of quantitative analysis, "As we watched Susan's struggles with identifying matched comparison 
groups for her quantitative analysis, I started to understand the 'art' involved in statistical analysis." Susan also reflected on how her research approach was 'eye-opening' to the rest of the group, "The quantitative methods I used for my dissertation provided the group with an ongoing alternative paradigm to discuss. At one point, the group decided that quantitative studies are not as 'cut and dried' as they might seem.

Team members stated that participating in a successful peer debriefing group encouraged an awareness of and appreciation for replicating this same type of experience with others to enrich future research projects. Carly summarized the thought this way:

But of utmost importance, I believe that the participation in a peer debriefing group not only gave me necessary foundational research skills for the field of academia, but provided me with the understanding that I could seek out and rely upon getting support from colleagues in new situations.

Carly added that one of the benefits she gained from her experience with this peer debriefing group was learning what was important in the selection of peer debriefers to review her current research. She admits that she seeks out a peer debriefer who is skilled at reviewing her coding and categorization process in order to identify bias and sources of bias. She prefers a peer debriefer with this knowledge rather than one with content knowledge expertise.

\section{Theme 3: The academic and emotional support provided by a peer debriefing group is a motivating factor leading to researcher's perceptions of success.}

Academic and emotional support emerged as a third theme in data analysis as it was frequently referred to by all participants. The team members described multiple forms of 'academic support,' including suggestions for literature reviews, advice on data collection and analysis, and reviewers of writing drafts. For example, Catherine was relieved to discover that Carly had recently reviewed literature on teachers' beliefs, which was an area where she needed additional literature resources. Susan felt better prepared in her research process because "our time together allowed me the opportunity to discuss research logistics, appropriate software tools, and important contacts [such as] transcribers or librarians." Team members helped each other address problems and concerns with data collection. Catherine explained:

As I became frustrated with one of my teacher informants in my constructivist-based study, my fellow peer debriefers helped me identify topics I could go back and ask him about in order to encourage him to expand further. And then they helped me realize that I may have simply reached saturation with this particular teacher.

This level of support not only "got us through the dissertation" but actually helped make each member's work better. Isabelle said, "I believe that being part of the group helped all of us make progress on our research projects and improved the quality of our work."

An even heavier emphasis on support was sought and received by each team member during data analysis. The team served as a 'sounding board' as individuals worked through the complex process of making meaning from data. A great deal of time in team meetings was spent discussing and reviewing raw data, emergent codes, or category generation. The team helped Jeanne analyze qualitative data for an evaluation study. When Isabelle needed to establish interrater reliability for the coding of her data, Susan immediately agreed to help her. Catherine also felt she benefited directly from the group's input on her analysis. She said, "My peer debriefing group by far helped me the most. They provided an external check of my work and therefore supported the credibility of the study." 
The process helped team members gain clarity and communicate before and during the writing of the results sections. As Carly said, "The group served as a safe haven for practicing research skills and procedures." The word 'safe' was mentioned also by Susan when she talked about the peer debriefing team, "The safe environment of this group allowed me to verbalize my thoughts." Susan expanded on this further when she discussed the support she received from her team when she was getting tough questions from her committee members on her analysis:

When my dissertation chair said that the discussion of the analysis seemed sparse, the peer group was able to remind me that this research analysis did not capture all types of learning outcomes; rather it focused strictly on achievement measured by one type of standardized assessment instrument.

Members further expressed that they expected participation in the team would impact the dissertation research, but the emotional support received from participation in the group was, and still is, the thread that keeps the team functioning together as friends and colleagues. The ups and downs of navigating through the rocky waters of graduate school were, at time, frustrating, and each member described how they profited from each others' experiences. Details such as meeting all the course requirements, turning in the university paperwork by specified deadlines, scheduling with committee members, preparing for a dissertation defense, and understanding how to actually turn in the dissertation, required constant attention. As Catherine explained:

It would have been overwhelming to navigate this alone . . Carly and Susan, who were

further along than Isabelle and I, were very helpful in suggesting when to schedule committee meetings, when to distribute the proposals, and how to handle the 'ruler lady' in the Graduate School when it came time to turn in my dissertation.

Jeanne was able to go into her doctoral qualifying exams more prepared with the help of exam preparation materials others had collected- "another benefit of the peer debriefing, and [a] form of scaffolding," remarked Jeanne.

Since their personal lives so directly affected what was happening in their doctoral work, the team members often looked to the peer debriefing group for this support as well. Comments from several members indicated that emotional support from the group kept the doctoral work in equilibrium with their personal lives. Isabelle explained the importance of maintaining this balance:

We spent a few minutes [during meetings] talking about what was happening in our personal lives so we understood some of the other factors influencing or impeding each other's work. However, we always spent the majority of our time working on our research. Over time, I think this balance allowed our group to feel like a safe place to me both professionally and personally.

It was important to team members to have a group of colleagues who could be called upon for brainstorming conversations, idea generation, review, and reflection during the research process. Team members expressed that they felt re-energized and ready to continue the process. Sometimes individual team members just needed people willing to listen. Catherine said, "There were few other people in my life that would want to listen to the details of my research, but these women did." And Isabelle continued, "There was a definite emotional aspect to being a part of this group. We encouraged each other and celebrated each others' accomplishments throughout the process." Jeanne completed her doctoral studies after the case studies were constructed for this research, and she added that the inspiration and confidence to finish came from knowing that the other members of the group, who finished ahead of her, believed in her:

When I was discouraged and ready to quit, I would pull up one of my peer group 
member's dissertations, or send an e-mail about the complexities of trying to continue my studies with the demands of my current job . . . and the support I needed to continue was there.

Catherine added that she felt supported as her family grew:

I juggled a growing family-I literally began graduate school with no children, and ended almost five years later with three. It wasn't easy, but my peer debriefing group never questioned my choices and whether I would be able to get back into my work. They rejoiced with me about my children and encouraged me in my trek through graduate school.

The experience of participating in a group that strongly supported its members, both academically and emotionally, laid the foundation for the most long-lasting benefit of participating in a peer debriefing group-a network of colleagues with whom they shared this intimate working knowledge. Even though members knew at the time of their participation in the team that all would be supported in some capacity, the depth and importance of that support to their graduate experiences was not realized until members were engaged in their professional careers. Carly explained that, after working with many colleagues at the university level, she could see how enriched her graduate experience had been compared to others, and her ability to work with groups simplified some of the struggles she saw other new faculty members having with conducting research projects and committing to the research/publishing cycle. Catherine expressed the underlying sentiments found in all of the participant statements when she commented, "They were more than peers; they were true friends."

\section{Discussion and Implications}

At the onset, the purpose of the group members was to form a peer debriefing team, a compulsory requirement of the graduate program in which they were enrolled, to substantiate the credibility of the research studies being conducted to fulfill the doctoral degree. Peer debriefing is an important strategy in establishing the trustworthiness of qualitative research studies, and guidelines about who should be included in the process and what should happen during peer debriefing sessions have been suggested by Erlandson et al. (1993) and others (e.g., Lincoln \& Guba, 1985, and Spall, 1998). Spillett (2003) provided detailed suggestions for finding debriefers, frequency and duration of meetings, specific activities to undertake during sessions, the type of dialogue that should occur, and how to address the peer debriefing in the research report.

Even though many sources explain the technicalities of conducting peer debriefing meetings, the peer debriefing team in this study witnessed the break-up of many other peer debriefing teams employed by their fellow graduate students. Conducting peer debriefing meetings and participating in the peer debriefing process is not as simple as the technical descriptions, and warrants further explanation (Cook, 1998). The findings identified the components of a successful peer debriefing team. A successful peer debriefing team is one in which the team members demonstrate a commitment to the group, continuity and consistency in attending meetings, and an interest in assuring that individual members of the team meet their expected learning needs. Similar to Spall's (1998) findings, the team meetings of this group evolved into a trusting environment that improved the quality of research work and helped team members develop their research skills and served as support as they moved through the dissertation process (Ely et al., 1991; Fitzpatrick, Secrist, \& Wright, 1998; Germeroth, 1991; 
Stalker, 1991).

In addition, the emotional support gained from being a part of a group was an important aspect of the peer debriefing team experience. As Ely et al. explained, "There is nothing like being in the same boat and cheering on your fellow paddlers" (p. 99). Participation in the team was a critical piece in completing their dissertations as all five of the team members finished their degrees. The fifth person, Jeanne, continued to find support for completing her dissertation through the team's long-distance network and completed her degree in 2007.

Evidence of the long-lasting power of a positive peer debriefing group experience were presented in the findings. Team members learned that it may not be the background or research focus of the possible peer debriefers that are of primary importance, but rather their commitment to the process and responsibilities of being a critical friend, with a dedication and desire to support others' learning experiences. The findings further suggest that teacher researchers, interested in utilizing peer debriefers, or critical friends, as a part of their research plans, will benefit from using a careful, thoughtful process in selecting individuals to serve in this capacity. Teacher researchers should identify individuals willing to commit to a process of critiquing and sharing that is consistent, continues over time, and is respectful of the learning needs of both teacher researcher and peer debriefer. These individuals should be able to provide emotional support as well as academic support, as personal lives of teacher researchers often impact the quality of the finished research or smoothness of the research process.

The impact of participation in a peer debriefing team as an important development step in preparation as a professional researcher and educator was also highlighted in the findings. Costa and Kallick (1993) describe these skills as asking provocative questions, interpreting data through another lens, and offering critiques of another's work as a friend. Friendships develop and are heightened by the trust that evolves between researcher and debriefer, which leads to a high potential for learning (Dysthe, 2002). Wennergren and Ronnerman (2006) state that to stimulate professional development of research skills, action researchers must be "socially and critically" supported by members of the team (p. 566). Three members of this peer debriefing team, Isabella, Carly, and Jeanne, have continued in careers as university professors, working with undergraduate and graduate students or in-service teachers, employing action research to investigate topics of interest. The scaffolding techniques learned in their peer debriefing team have been assimilated into their own teaching practices, as they found themselves serving as peer debriefers or critical friends to their own students and colleagues. Susan continues her role as director of research in a university research institute, where she supports other researchers in various research projects; Catherine, a consultant for local museum, uses her skills to critique and evaluate programs for the museum; and Jeanne employs her skills in her work as a mentor and critical friend to her online doctoral students.

However, each member's personal reasons for committing to such a team over the longterm was clearly that their individual expectations of what each would receive from the group in return for their participation - quality feedback, an objective critique of interpretations, and a trusted friendship that encouraged the success of our work-evolved into a consistent and continuing network of critical friends. Teacher researchers should be advised of the benefits of drawing upon the expertise of critical friends, or participating in a peer debriefing team. Not only is the quality of teacher research enhanced by building these types of relationships, resulting in a superior research product, but participation in such an experience validates the importance of the teacher researchers' efforts. 


\section{References}

Atay, D. (2008). Teacher research for professional development. ELT Journal, 62(2), 139-147.

Baumann, J. F., \& Duffy, A. M. (2001). Teacher-researcher methodology: Themes, variations, and possibilities. The Reading Teacher, 54(6), 608-615.

Bonner, P. J. (2006, Summer). Transformation of teacher attitude and approach to math instruction through collaborative action research. Teacher Education Quarterly, 27-44.

Briscoe, C., \& Wells, E. (2002). Reforming primary science assessment practices: A case study of one teacher's professional development through action research. Science Education, $86,417-435$.

Cook, T. (1998). The importance of mess in action research. Educational Action Research, 6(1), 93-109.

Costa, A. L., \& Kallick, B. (1993). Through the lens of a critical friend. Educational Leadership, 51(2), 49-51.

Creswell, J. W. (2005). Qualitative inquiry and research design: Choosing among five approaches. Thousand Oaks, CA: Sage.

Dysthe, O. (2002). The learning potential of a web-mediated discussion in a university course. Studies in Higher Education, 27(3), 339-352.

Ely, M., Anzul, M., Friedman, T., Garner, D., \& Steinmetz, A. M. (1991). Doing qualitative research: Circles within circles. New York: Falmer.

Erlandson, D. A., Harris, E. L., Skipper, B. L., \& Allen, S. D. (1993). Doing naturalistic inquiry: A guide to methods. Newbury Park, CA: Sage.

Figg, C., \& Jaipal, K. (May 2009). Symposium: Teachers Learning Together: Promoting Professional Growth through Collaborative Action Research. Paper presented at the 2009 AERA Annual Meeting, San Diego, CA.

Flake, C. L., Kuhs, T., Donnelly, A., \& Ebert, C. (1995). Reinventing the role of teacher: Teacher as researcher. Phi Delta Kappan, 76(5), 405-407.

Fletcher, S. (2002). What is teacher research? Wilshire Journal of Education. Retrieved September 23, 2009, from http://www.teacherresearch.net/rm_wiltshirespring02-3.htm

Fitzpatrick, J., Secrist, J., \& Wright, D. J. (1998). Secrets for a successful dissertation. Thousand Oaks: Sage. 
Fullan, M. (1995). Change Forces: Probing the Depths of Educational Reform. London: The Falmer Press.

Germeroth, D. (1991). Lonely days and lonely nights: Completing the doctoral dissertation. ACA Bulletin (76), 60-90.

Glazer, C., Abbott, L., \& Harris, J. (2004). A teacher-developed process for collaborative professional reflection. Reflective Practice, 5(1), 33 - 46.

Glesne, C. (1999). Becoming qualitative researchers: An introduction (2nd ed.). New York: Longman.

Gordon, J. (2006). Critical friendship. Medical Education, 40(1), 5 - 6.

Joyce, B., \& Showers, J. (2002). Student Achievement Through Staff Development. Alexandria, VA: Association for Supervision \& Curriculum Development (ASCD).

Kang, N. (2007). Elementary teachers' teaching for conceptual understanding: Learning from action research. Journal of Science Teacher Education, 18, 469 - 495.

Kraft, N. P. (2002). Teacher research as a way to engage in critical reflection: A case study. Reflective Practice, 3(2), 175 - 189.

Lincoln, Y. S., \& Guba, E. G. (1985). Naturalistic inquiry. Newberry Park, CA: Sage.

Little, J. W. (2002). Locating learning in teachers' communities of practice: Opening up problems of analysis in records of everyday work. Teaching and Teacher Education, $18(8), 917-946$.

Lytle, S. L., \& Cochran-Smith, M. (1990). Learning from teacher research: A working typology. Teachers College Records, 92, 83 - 103.

May, W. T. (1993). "Teachers-as-Researchers" or action research: What is it, and what good is it for art education? Studies in Art Education, 34(2), 114-126.

Meyers, E., Rust, F.\& Paul, P. (Eds.). (2006). The missing link: Connecting teacher research, practice, and policy to improve student learning. Teachers Leadership Network Institute. Retrieved September 2, 2009, from the TeacherNetwork at http://www.teachersnetwork.org/tnli/missinglink.pdf

Miles, M. B., \& Huberman, M. (1994). Qualitative data analysis: An expanded sources book. Thousand Oaks, CA: Sage Publications.

Patton, M. Q. (2002). Qualitative Research and Evaluation Methods. Thousand Oaks, CA: SAGE Publications. 
Savoie-Zajc, L., \& Descamps-Bednarz, N. (2007). Action research and collaborative research: their specific contributions to professional development. Educational Action Research, 15(4), $577-596$.

Schwandt, T. A. (1994). Constructivist, interpretivist approaches to human inquiry. In N. K. Denzin \& Y. S. Lincoln (Ed.), Handbook of Qualitative Research. Thousand Oaks, CA: Sage.

Spall, S. (1998). Peer debriefing in qualitative research: Emerging operational models. Qualitative Inquiry, 4(2), 280-292.

Spillett, M. A. (2003). Peer debriefing: who, what, when, why, how. Academic Exchange Quarterly, 7(3), 36-41.

Stalker, A. (1991). Misery loves company and other important functions of a dissertation support group. ACA Bulletin (76), 56-59.

Wennergren, A., \& Ronnerman, C. (2006). The relation between tools used in action research and the zone of proximal development. Educational Action Researcher, 14(4), 547-568.

Yin, R. K. (2008). Case study research: Design and methods. Thousand Oaks, CA: Sage Publications.

Zeichner, K., \& Klehr, M. (1999). Teacher Research as Professional Development for P-12 Educators. Eric Documents ED448156. Retrieved September 2, 2009, from http://www.eric.ed.gov/ERICWebPortal/custom/portlets/recordDetails/detailmini.jsp?_nf $\mathrm{pb}=$ true\&_\&ERICExtSearch_SearchValue_0=ED448156\&ERICExtSearch_SearchType _ $0=$ no\&accno $=$ ED 448156 